
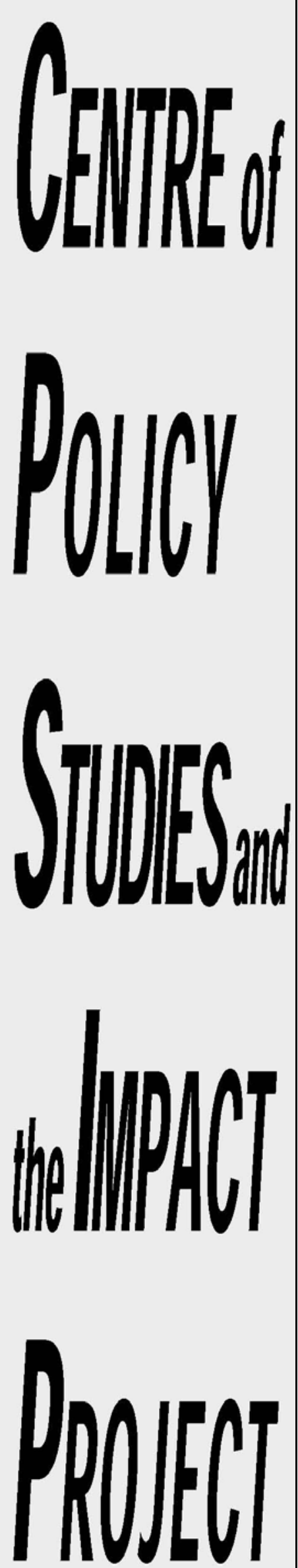

Eleventh Floor, Menzies Building Monash University, Wellington Road CLAYTON Vic 3800 AUSTRALIA

Telephone:

from overseas:

(03) 9905 2398, (03) 99055112

61399052398 or

61399055112

Fax:

(03) 99052426

61399052426

e-mail:

impact@buseco.monash.edu.au

Internet home page:

\title{
Effects on the U.S. of an H1N1 Epidemic: Analysis with a Quarterly CGE model
}

by

\author{
Peter B. DIXON \\ Centre of Policy Studies \\ Monash University \\ BUMSOO LEE
}

Dept of Urban and Regional Planning University of Illinois at Urbana-Champaign

TODD MUEHLENBECK CREATE

University of Southern California

MAUREEN T. RIMMER

Centre of Policy Studies

Monash University

ADAM Z. ROSE

CREATE

University of Southern California

AND

GeORge VERIKIOS

Centre of Policy Studies

Monash University

General Paper No. G-202 June 2010 



\title{
Effects on the U.S. of an H1N1 epidemic: analysis with a quarterly CGE model by \\ Peter B. Dixon ${ }^{1}$, Bumsoo Lee ${ }^{2}$, Todd Muehlenbeck ${ }^{3}$, Maureen T. Rimmer ${ }^{1}$, Adam Z. Rose ${ }^{3}$ and George Verikios ${ }^{1}$
}

\begin{abstract}
We simulate the effects of a hypothetical H1N1 epidemic in the U.S. using a quarterly CGE model. Quarterly periodicity allows us to capture the short-run nature of an epidemic. We find potentially severe economic effects in the peak quarter. Averaged over the epidemic year the effects are considerably damped. Our results indicate that the macroeconomic consequences of an epidemic are more sensitive to demand-side effects such as reductions in international tourism and leisure activities than to supply-side effects such as reductions in productivity. This suggests that demand stimulus policies might be an appropriate economic response to a serious epidemic.
\end{abstract}

Key words: Influenza epidemic; Quarterly CGE modelling.

JEL codes: I18; C68.

${ }^{1}$ Centre of Policy Studies, Monash University

2 Department of Urban and Regional Planning, University of Illinois at Urbana-Champaign.

${ }^{3}$ Center for Regional Economic Analysis of Terrorism Events (CREATE), University of Southern California. 


\section{Table of contents}

Summary 1

1. Introduction 1

2. Background on the USAGE model 2

3. USAGE simulations: setting the shocks 3

(S1) Inbound and outbound tourism 4

(S2) Labor input 5

(S3) Medical expenditures $\quad 5$

(S4) Expenditures by households on leisure activities
involving public gatherings

4. Results 6

Employment and GDP 6

$\begin{array}{ll}\text { Investment and capital } & 8\end{array}$

Expenditure components of GDP 8

$\begin{array}{lr}\text { Industry outputs } & 8\end{array}$

Relative importance of individual shocks for aggregate employment 14

5. Summary and concluding remarks 17

$\begin{array}{ll}\text { References } & 18\end{array}$

$\begin{array}{ll}\text { Appendix } & 19\end{array}$ 


\section{Summary}

We consider a hypothetical H1N1 epidemic that causes about 90 million people to be infected in 2010. Of these, about 30 million seek medical attention, with about 300,000 hospitalized and 16,000 deaths. We assume that the epidemic is concentrated over a 6 month period in which it causes:

(1) 34 and 17 per cent reductions in inbound and outbound international tourism (including business travel);

(2) a loss of 74 million days of labor input (a productivity reduction of about 0.4 per cent) associated with increased sick leave and absences from work by parents caring for sick children;

(3) a 2.4 per cent surge in demand for hospital and other medical services; and

(4) a 10 per cent cut in expenditures by households on leisure activities involving public gatherings with an associated 0.55 per cent reduction in the average propensity to consume.

Using a quarterly version of USAGE, a detailed, dynamic CGE model of the U.S., we find that these shocks would have the macroeconomic effects shown in Table 1 . The effects are quite severe at the height of the epidemic (peak quarter) and include a 2.1 per cent reduction in employment. Averaged over the epidemic year the effects are considerably damped. In the year following the epidemic, the effects are mostly positive. By reducing wage rates, the epidemic improves the competitive position of the U.S. economy in the post-epidemic year.

Table 0. USAGE results for the effects of an H1N1 epidemic (Percentage deviations from baseline)

\begin{tabular}{lccc}
\hline Variable & Peak quarter & Epidemic year & Next year \\
\hline Employment & -2.1 & -1.3 & 0.3 \\
GDP & -2.6 & -1.6 & 0.2 \\
Private consumption & -3.2 & -2.1 & -0.1 \\
Investment & -4.3 & -3.1 & 0.5 \\
Exports & -4.7 & -2.7 & 1.0 \\
Imports & -5.7 & -4.5 & -0.3 \\
\hline
\end{tabular}

\section{Introduction}

In mid-2009 it seemed likely that the U.S. would face an H1N1 influenza epidemic in the winter of 2009-10. Fears were held that the epidemic could be as serious as those of 1957 and 1968 which caused approximately 70,000 and 34,000 deaths in the U.S., and possibly even as serious as the 1918 epidemic which killed about 500,000 U.S. residents. Such epidemics are not only a medical crisis, but may have significant economic effects. This paper explores these potential economic effects. Fortunately, it now appears that H1N1 will not be as devastating in 2010 as was first feared. 
Nevertheless, investigation of the economic effects of a major epidemic is still of interest as an input to contingency planning.

In carrying out our investigation, we use a dynamic, computable general equilibrium (CGE) model of the U.S. This is not the first time that a CGE model has been applied in quantifying the potential effects of an epidemic. McKibbin and Sidorenko (2006) provide an extensive survey of the relevant modeling literature and report simulation results from a global CGE model of the effects of pandemics of various degrees of severity. Unlike McKibbin and Sidorenko, we focus entirely on the U.S. ${ }^{4}$ This narrower focus allows for more detail in at least two dimensions: industries and periodicity. Whereas the McKibbin-Sidorenko model distinguishes six sectors, the model used in this paper identifies 39 sectors including sectors that are particularly relevant to the study of the economic effects of epidemics such as medical services and inbound and outbound tourism. With respect to periodicity, our model is quarterly whereas the models of all other CGE contributors to this literature, including McKibbin and Sidorenko, are annual ${ }^{5}$. Quarterly periodicity is an important advantage in modeling epidemics which tend to have sharp effects over periods much shorter than a year.

The remainder of the paper is organized as follows. Section 2 describes the USAGE model which we use in our simulations. Section 3 describes the shocks that we apply. Section 4 sets out and explains the results. A summary of results together with concluding remarks are in section 5 .

\section{Background on the USAGE model}

$\mathrm{USAGE}^{6}$ is a detailed, dynamic, CGE model of the U.S. It has been developed at the Centre of Policy Studies, Monash University, in collaboration with the U.S. International Trade Commission. ${ }^{7}$ The theoretical structure of USAGE is similar to that of the MONASH model of Australia (Dixon and Rimmer, 2002). However, in both its theoretical and empirical detail, USAGE goes beyond MONASH. USAGE can be run with up to 500 industries, 700 occupations and 51 regions (50 States plus the District of Columbia). In the application reported in this paper we use a version of the model in which there are 39 industries.

USAGE includes three types of dynamic mechanisms: capital accumulation; liability accumulation; and lagged adjustment processes. Capital accumulation is specified separately for each industry. An industry's capital stock at the start of period $\mathrm{t}+1$ is its capital at the start of period $\mathrm{t}$ plus its investment during period $\mathrm{t}$ minus depreciation. Investment during period $t$ is determined as a positive function of the expected rate of return on the industry's capital. ${ }^{8}$ Liability accumulation is specified for the public sector and for the foreign accounts. Public sector liability at the start of period

\footnotetext{
4 This is also the focus of CBO (2006) which looks at the effects on the U.S. of two Avian influenza scenarios. While detailed and quantitative, the CBO report does not use a formal economic model.

${ }^{5}$ Bloom et al. (2005) undertake a pandemic analysis with a quarterly model. However their model is macro econometric (no industry dimension) rather than CGE.

${ }^{6}$ U.S. Applied General Equilibrium.

7 Prominent applications of USAGE by the U.S. International Trade Commission include USITC (2004, 2007 and 2009).

8 The investment specification for the MONASH model, adopted in USAGE, is discussed in detail in Dixon et al. (2005)
} 
$\mathrm{t}+1$ is public sector liability at the start of period $\mathrm{t}$ plus the public sector deficit incurred during period t. Net foreign liabilities at the start of period $t+1$ are specified as net foreign liabilities at the start of period $t$ plus the current account deficit in period t plus the effects of revaluations of assets and liabilities caused by changes in price levels and the exchange rate. Lagged adjustment processes are specified for the response of wage rates to gaps between the demand for and the supply of labor by occupation.

In a USAGE simulation of the effects of policy and other shocks, we need two runs of the model: a baseline or business-as-usual run and a policy run. The baseline is intended to be a plausible forecast while the policy run generates deviations away from the baseline caused by the shocks under consideration (e.g. an outbreak of H1N1 influenza). The baseline incorporates trends in industry technologies, household preferences and trade and demographic variables. These trends are estimated largely on the basis of results from historical runs in which USAGE is forced to track a piece of history. Most macro variables are exogenous in the baseline so that their paths can be set in accordance with forecasts made by expert macro forecasting groups such as the Congressional Budget Office. This requires endogenization of various macro propensities, e.g. the average propensity to consume. These propensities must be allowed to adjust in the baseline run to accommodate the exogenous paths for the macro variables.

The policy run in a USAGE study is normally conducted with a different closure (choice of exogenous variables) from that used in the baseline. In the policy run, macro variables must be endogenous: we want to know how they are affected by the shocks under consideration. Correspondingly, macro propensities are exogenized and given the values they had in the baseline. More generally, all exogenous variables in the policy run have the values they had in the baseline, either endogenously or exogenously, with the exception of the variables of interest. Comparison of results from the policy and baseline runs then gives the effects of shocking the variables of interest away from their baseline values.

For this paper, the baseline and policy runs differ with regard to the values given to exogenous variables representing an outbreak of H1N1 influenza. We interpret the differences between the results in the baseline and the policy runs as the effects of the outbreak.

In previous applications, the USAGE model produced annual results. For the current application, the model has been modified so that it produces quarterly results. This modification is important because it is likely that an epidemic will have sharp effects over a short period. An annual model tends to smooth out effects leading to potential underestimation of disruption. For example, if an epidemic caused an 80 per cent loss of inbound international tourism for a particular quarter, then the adjustment path of the tourism industry would be quite different from that in a situation in which international tourism declined by 20 per cent for a year. Similarly, a 4 per cent increase in a single quarter in demands for medical services related to infectious diseases would place more stress on the medical system than a 1 per cent increase spread over a year.

\section{USAGE simulations: setting the shocks}

More detail on the material contained in this section can be found in the Appendix. 
We consider a hypothetical H1N1 epidemic that causes 88.6 million people to be infected in the first two quarters of 2010. Of these people, 59.8 million experience symptoms. This scenario is derived from agent-based modeling carried out by Josh Epstein of the Brookings Institution and includes not only these aggregate figures but also a breakdown by age group. Epstein's scenario is quite similar to the two scenarios considered by CBO (2006) in which 75 million and 90 million people are infected by Avian influenza.

Reed et al. (2009) gives detailed statistics on medical treatment, hospitalization and death in the U.S. from H1N1 over the four-month period April 2009 to July 2009. During this period about 3 million U.S. residents experienced symptomatic infection. Based on the experience reported by Reed et al., we estimate that if 59.8 million people were to become symptomatic then 29.9 million (half those experiencing symptoms) would seek medical attention. Of these, 269,000 would be hospitalized with 16,000 deaths.

An H1N1 epidemic that caused symptomatic infection for 59.8 million U.S. residents over a six month period would impart a number of shocks to the U.S. economy. We think the most important would be: a reduction in both inbound and outbound international tourism (which we will refer to as shock S1) ; a loss of labor input (S2); an increase in medical expenditures (S3); and a reduction in expenditures on leisure activities involving public gatherings (S4).

In is not possible to be precise on the size of these shocks. However, we can hypothesize about orders of magnitude and use our economic model to work out which shocks are likely to be the most significant. For concreteness we make the following assumptions:

(S1) inbound and outbound tourism fall 34 and 17 per cent respectively below their baseline levels in 2010.Q1 and Q2 and then recover smoothly to their baseline levels over the next four quarters. In setting the shock for inbound tourism we considered the experiences with inbound tourism to Asia during the Asian SARS epidemic of 2003 and to Mexico during the H1N1 outbreak in Mexico in April to July 2009. These episodes suggest that regions suffering a widespread influenza infection can incur reductions in inbound tourism in the range 20 to 70 per cent during the peak infection period. For our hypothetical H1N1 epidemic, a disease with generally mild symptoms and low lethality, we adopt a number (34 per cent) towards the lower end of this range. One possibility for outbound tourism is a zero effect consistent with no U.S. residents being dissuaded from vacationing overseas. However, it is reasonable to suppose that some potential U.S. travelers would be dissuaded from international travel by fears of becoming symptomatic on vacation: they may already be infected but not yet symptomatic; they may contract influenza from a fellow passenger; or they may contract influenza on arrival at their destination as the epidemic spreads. While we would not expect the effect of a U.S.-centered epidemic on outbound tourism to match that on inbound tourism, we would expect a significant contraction in outbound tourism. For illustrative purposes we assume that the outbound effect is half that of the inbound effect. We also assume that U.S. residents who are dissuaded from 
international tourism save their tourism budget implying a reduction in the average propensity to consume by the household sector of 0.238 per cent.

(S2) labor input from employed workers falls 0.41 per cent below its baseline level in 2010.Q1 and Q2 and then recovers to its baseline level in 2010.Q3. In arriving at this shock, we assumed that during 2010.Q1 and Q2 there would be a loss of 74.0 million days work directly related to H1N1 through sickness of workers and absence from work due to taking care of sick children. With about 150 million workers in the U.S. contributing 120 days each in a six-month period, this loss of work days amounts to a 0.41 per cent loss of labor input per worker [0.41= $100 * 74.0 /(150 * 120)]$. Table 1 shows our calculation of work days lost. The first column of numbers is derived from Epstein's scenario. The factors in the second column show lost workdays per person in the first column. For working age people (18-64) these factors were suggested by Molinari et al. (2007) in their study of seasonal influenza. ${ }^{9}$ For children (0-17), we follow Molinari et al. in assuming that missed childcare and school days for symptomatic children conform to the same pattern as missed workdays for adults. Then based on data from the American Community Survey on the proportion of children in families with no non-working parent, we assume that each missed childcare/school-day results in 0.7 missed workdays for a caring parent if the child is at home and 0.35 missed workdays if the child is hospitalized. The final column in Table 1 is the product of the previous two columns. As well as a 0.41 per cent reduction in labor input per employed worker, shock (S2) introduces a permanent reduction in the supply of labor of 0.0053 per cent ${ }^{10}$. This represents the effect on the workforce of H1N1-related deaths in our hypothetical scenario. The economic effect of this reduction in labor supply is negligible.

(S3) medical expenditures move 2.41 per cent above their baseline levels in 2010.Q1 and 2010.Q2 and then return to their baseline level in 2010.Q3. As shown in Table 2, we estimate for our H1N1 scenario that medical expenditures would be increased by $\$ 14.15$ billion (2003\$s) in the six-month epidemic period, which in current prices is 2.41 per cent of half a year's medical expenditures. The cost-per-person figures in Table 2 are taken from Molinari et al. (2007).

(S4) expenditures by households on leisure activities involving public gatherings move 10 per cent below their baseline levels in 2010.Q1 and 2010.Q2 and then return to their baseline level in 2010.Q3. Following CBO (2006) we assume that these expenditures represent 4 per cent of GDP and cover arts, entertainment, accommodation and food service. In setting the 10 per cent shock, we also followed CBO (2006) who, in their mild-Avian-influenza scenario, assumed a 20 per cent cut in these expenditures for a single quarter (equivalent to a 10 per cent cut for two quarters). As in (S1) we assume that U.S. residents who refrain from expenditures because of H1N1 save their money, implying a further reduction in the average propensity to consume by the household sector of 0.549 per cent.

\footnotetext{
${ }^{9}$ Molinari et al.'s estimates take account of workforce participation rates.

10 About 8,000 deaths of people in the workforce out of a total workforce of 150 million.
} 
Table 1. Calculation of lost workdays

\begin{tabular}{lccr}
\hline & $\begin{array}{c}\text { People aged 18-64 } \\
\text { (millions) }\end{array}$ & $\begin{array}{c}\text { Workdays lost per } \\
\text { person }\end{array}$ & $\begin{array}{c}\text { Workdays lost } \\
\text { (millions) }\end{array}$ \\
\hline Symptoms, but no medical treatment & 14.01 & 0.50 & 7.01 \\
Medical treatment without hospitalization & 13.87 & 2.40 & 33.29 \\
Hospitalized & 0.14 & 13.90 & 1.93 \\
\hline \multicolumn{4}{c}{ People aged 0-17 } \\
(millions) & & \\
\hline Symptoms, but no medical treatment & 15.48 & $0.35(=0.7 * 0.50)$ & 5.42 \\
Medical treatment without hospitalization & 15.36 & $1.68(=0.7 * 2.40)$ & 25.81 \\
Hospitalized & 0.12 & $4.87\left(=0.35^{*} 13.90\right)$ & 0.57 \\
\hline Total workdays lost & & & 74.04 \\
\hline
\end{tabular}

Table 2. Calculation of medical expenditures (\$2003)

\begin{tabular}{lrcc}
\hline & People (millions) & Cost per person (\$) & Total cost (\$billion) \\
\hline Symptoms, but no medical treatment & 29.907 & 3 & 0.09 \\
Medical treatment without hospitalization & 29.622 & 293 & 8.68 \\
Hospitalized and survived & 0.254 & 18,298 & 4.65 \\
Hospitalized and died & 0.016 & 46,120 & 0.74 \\
\hline Total & 59.80 & & 14.15 \\
\hline
\end{tabular}

\section{Results}

This section reports USAGE results for the effects of the shocks described in section 3. We start with macro and industry effects of the four sets of shocks combined. Then we analyse the results for aggregate employment in more detail by describing the effects of each set of shocks individually.

\section{Employment and GDP}

Chart 1 shows the effects of the shocks on aggregate employment and GDP. The main effect occurs in 2010.Q2 when employment falls 2.1 per cent below the baseline. The reduction in GDP is even larger, 2.6 per cent in 2010.Q2. The decline in GDP relative to employment mainly reflects the loss in productivity imposed in (S2). On average through 2010, the epidemic reduces aggregate employment by 1.3 per cent and GDP by 1.6 per cent. Both aggregate employment and GDP are a little higher in 2011 with the 2010 epidemic than they would have been without it. Through 2011, Chart 1 shows average positive deviations for employment and GDP of 0.3 per cent and 0.2 per cent. As indicated in Chart 2, the epidemic-related reduction in employment in 2010 causes real wage rates to be lower than they otherwise would have been. This allows the U.S. to arrive in 2011 with enhanced international competitiveness so that when tourism recovers and the other epidemic-related shocks disappear, employment and output move above their baseline values. 
Chart 1. Effects of the hypothetical epidemic on aggregate employment and GDP (percentage deviations from baseline)

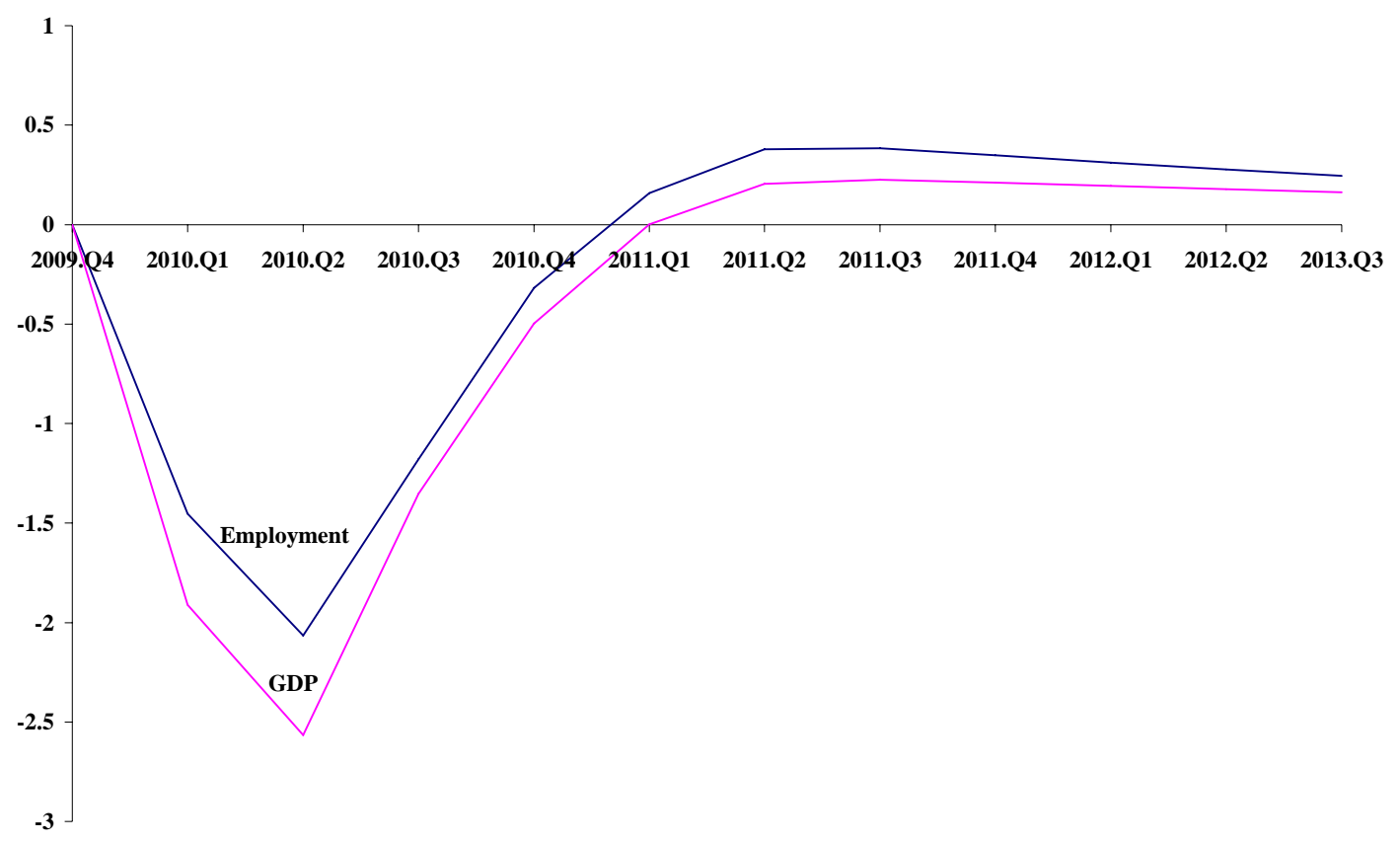

Chart 2. Effects of the hypothetical epidem

ic on aggregate employment and the real wage rate (percentage deviations from baseline)

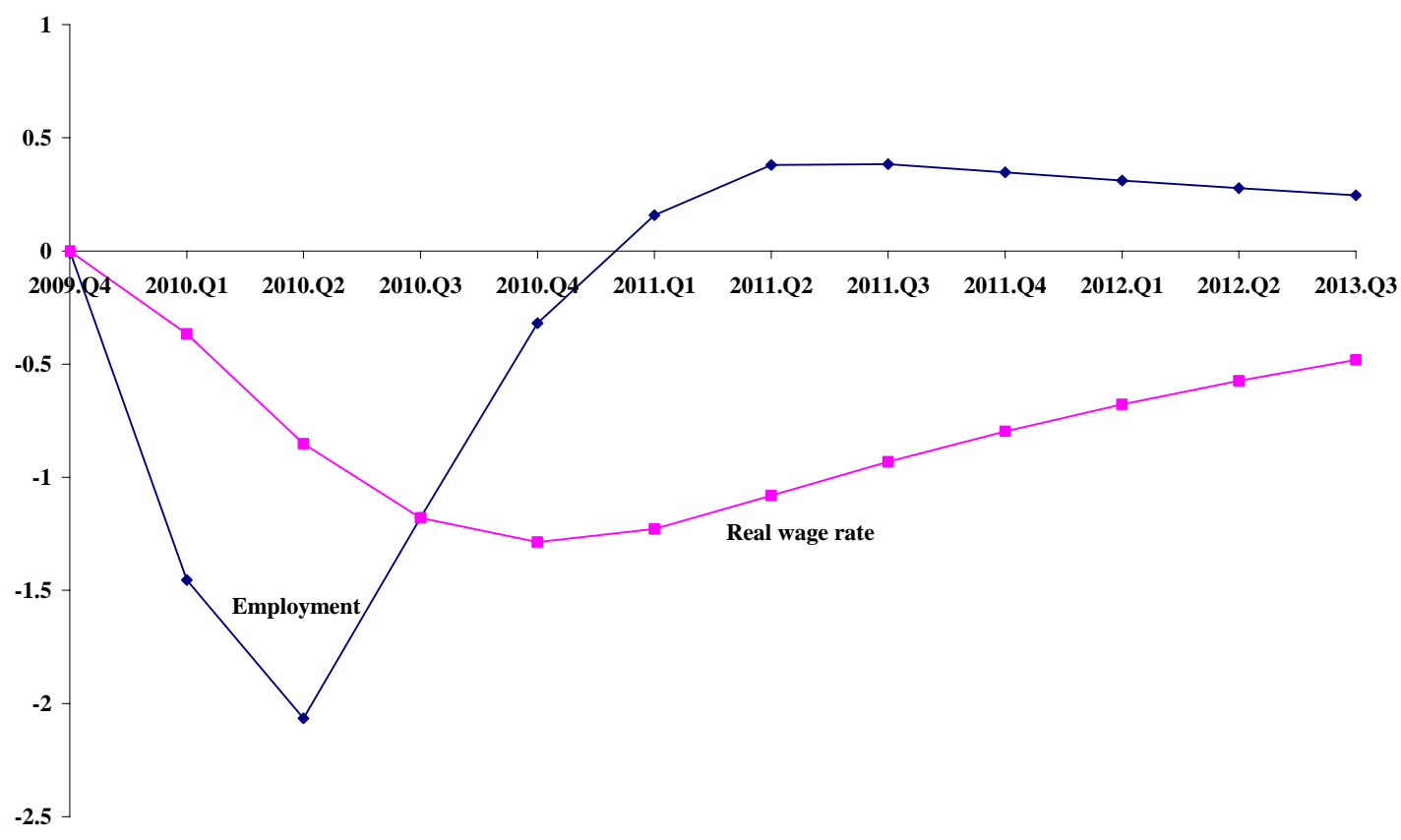




\section{Investment and capital}

Chart 3 shows that the hypothetical epidemic reduces investment: by 0.7 per cent in 2010.Q1; by 4.3 per cent in 2010.Q2; and by 4.9 per cent in 2010.Q3. In 2010.Q1, investment falls below the baseline because demand-contracting [(S1) and (S4)] and costincreasing [(S2)] shocks reduce the rental value of capital. This damps expected rates of return and thereby reduces investment. It is also true that in 2010.Q1 the epidemic causes excess capacity to appear in some industries, particularly those related to tourism and construction. Excess capacity in 2010.Q1 has a strongly negative effect on in investment in 2010.Q2. Weak investment in 2010.Q2 causes further excess capacity to appear, explaining weak investment in 2010.Q3. In 2010.Q3, much of the pick up in demand for capital associated with the recovery in the demand for leisure activities and the start of the recovery in tourism is satisfied by working down the excess capacity that appeared in 2010.Q1 and 2010.Q2. By 2010.Q4 investment starts to move back towards the baseline. This is because excess capacity in 2010.Q3 is declining as capital in existence adjusts down and capital in use adjusts up, Chart 4. By 2011.Q2, excess capacity is eliminated (that is, capacity utilization is at normal levels).

\section{Expenditure components of GDP}

Chart 5 shows epidemic-induced movements in the real expenditure components of GDP. Exports decline sharply in 2010.Q1 reflecting the 34 per cent reduction in inbound tourism $^{11}$ (S1). Although inbound tourism does not fully recover until 2011.Q2, aggregate exports move back close to their baseline path by 2010.Q3. The recovery of exports is assisted by real devaluation (Chart 6) associated with weak investment (already discussed). Imports decline sharply in 2010.Q1 and 2010.Q2. This reflects three factors: the reduction in outbound tourism ${ }^{12}$; real devaluation; and the decline in GDP. Private consumption closely follows the path of real GDP. Public consumption is treated exogenously and assumed not to be affected by the epidemic.

\section{Industry outputs}

USAGE results for the effects of the hypothetical epidemic on outputs of groups of selected industries are given in Charts 7 to 12 . Chart 7 covers industries that are directly impacted by the epidemic. Output of Medical services is stimulated in the first half of 2010 by about 2 per cent through (S3). Inbound and Outbound tourism contract in the first half of 2010 by about 34 and 17 per cent respectively through (S1). Miscellaneous services contracts by about 4 per cent through the direct shock applied in (S4) and through the general contraction in economic activity.

Chart 8 shows sharp short-run contractionary effects for industries supplying inputs to investment. In 2010.Q3, output of construction is about 5.3 per cent below its baseline and remains below baseline until 2011.Q2. Other investment-supplying industries benefit from their trade exposure. For example, the outputs of Machinery, Electrical machinery, Computers and Transport equipment are above their baselines by 2010.Q4, even though aggregate investment is still well below its baseline (Chart 3).

\footnotetext{
11 Inbound tourism contributes about 14 per cent of U.S. exports.

12 Outbound tourism accounts for about 3 per cent of U.S. imports.
} 
Chart 3. Effects of the hypothetical epidemic on aggregate investment (percentage deviations from baseline)

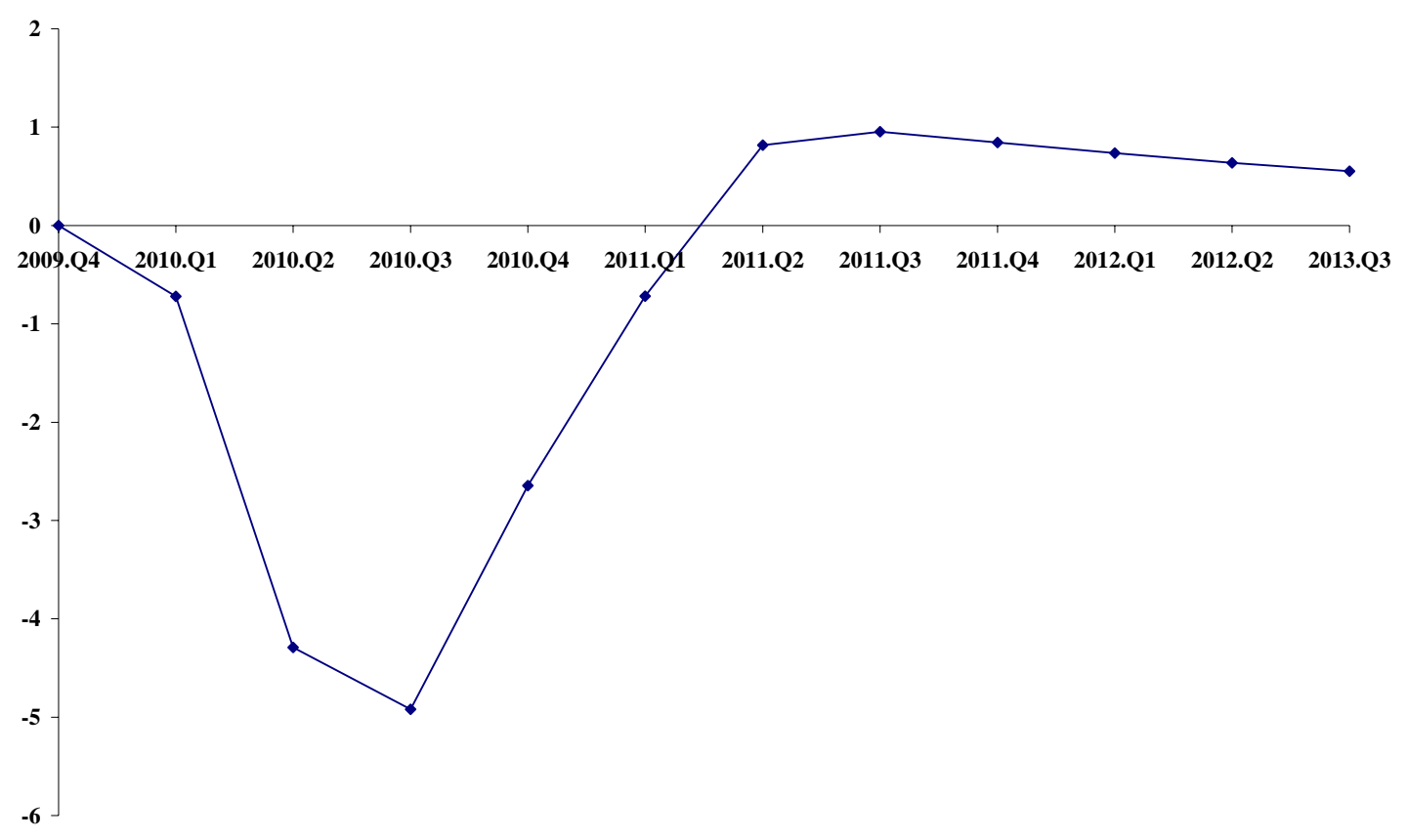

Chart 4. Effects of the hypothetical epidemic on aggregate investment and capital (percentage deviations from baseline)

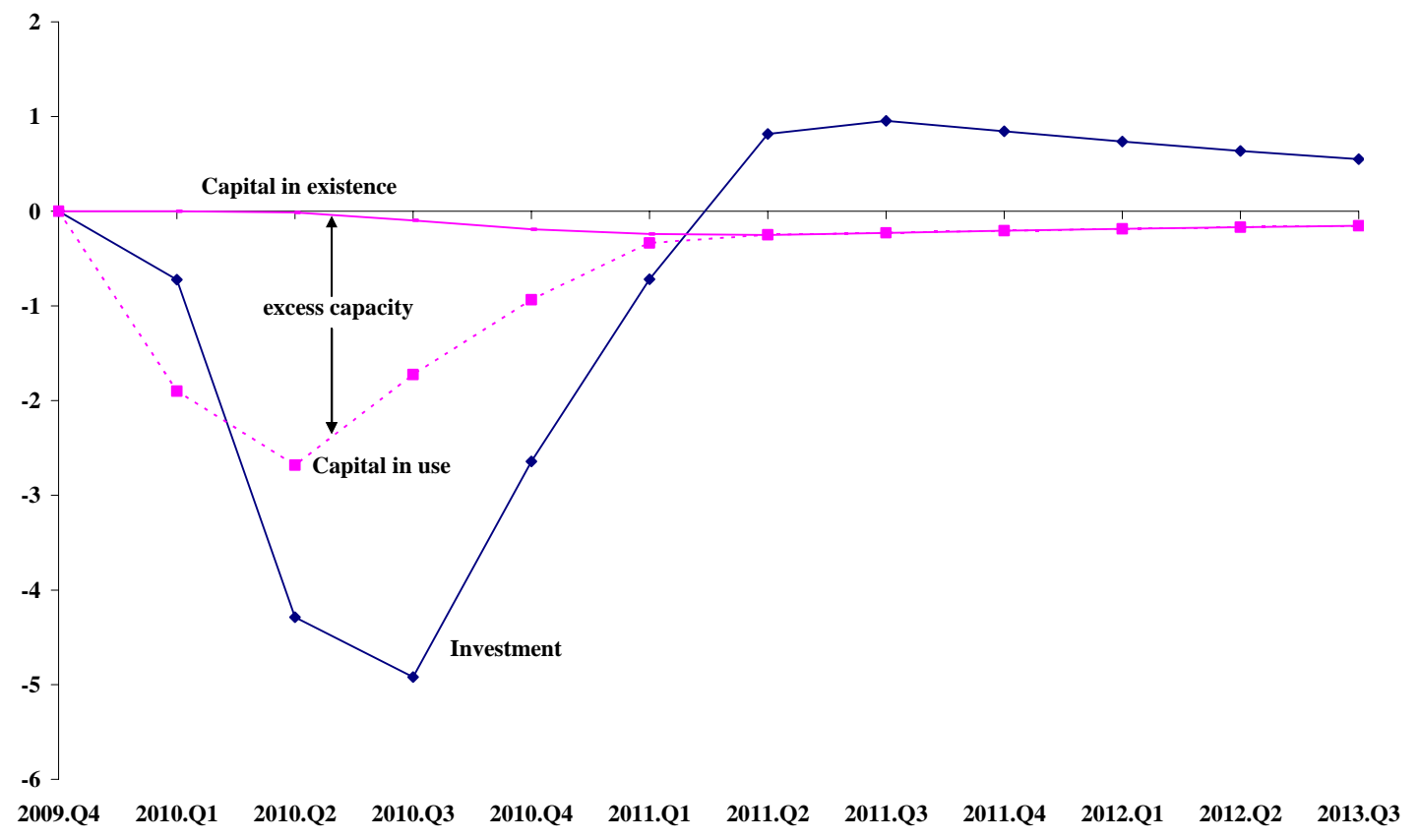


Chart 5. Effects of the hypothetical epidemic on expenditure components of GDP (percentage deviations from baseline)

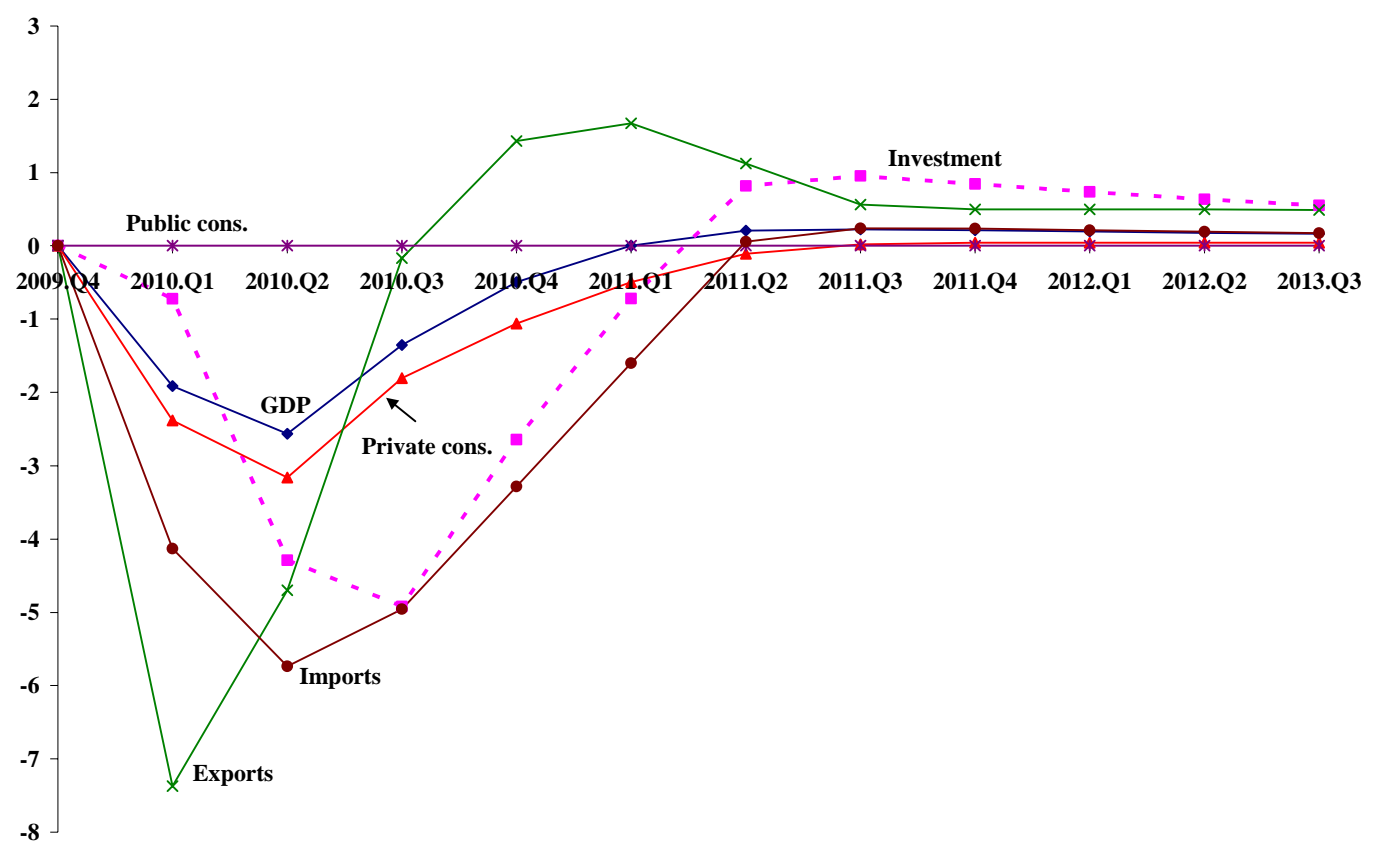

Chart 6. Effects of the hypothetical epidemic on the real exchange rate (percentage deviations from baseline)

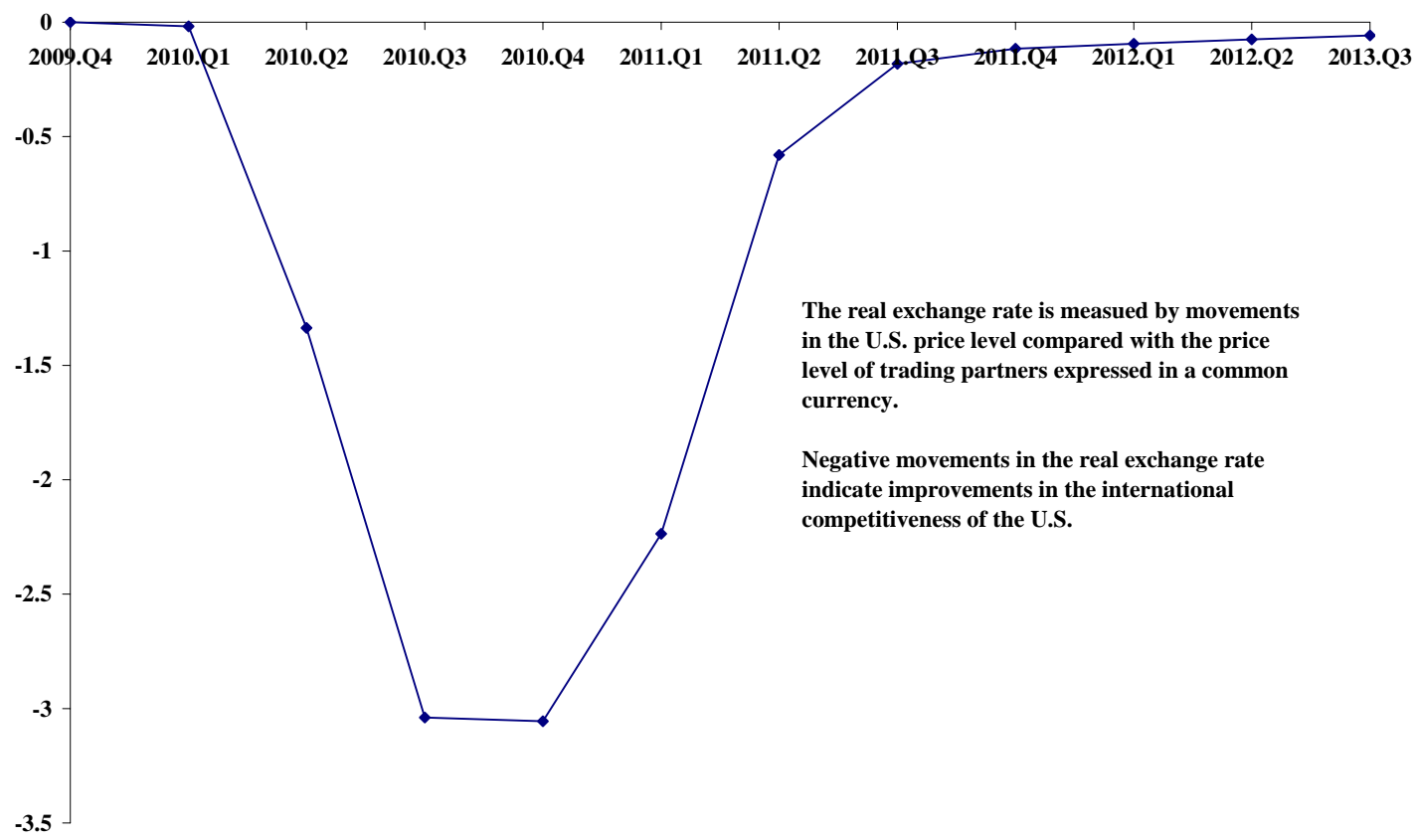


Chart 7. Effects of the hypothetical epidemic on output of directly impacted industries (percentage deviations from baseline)

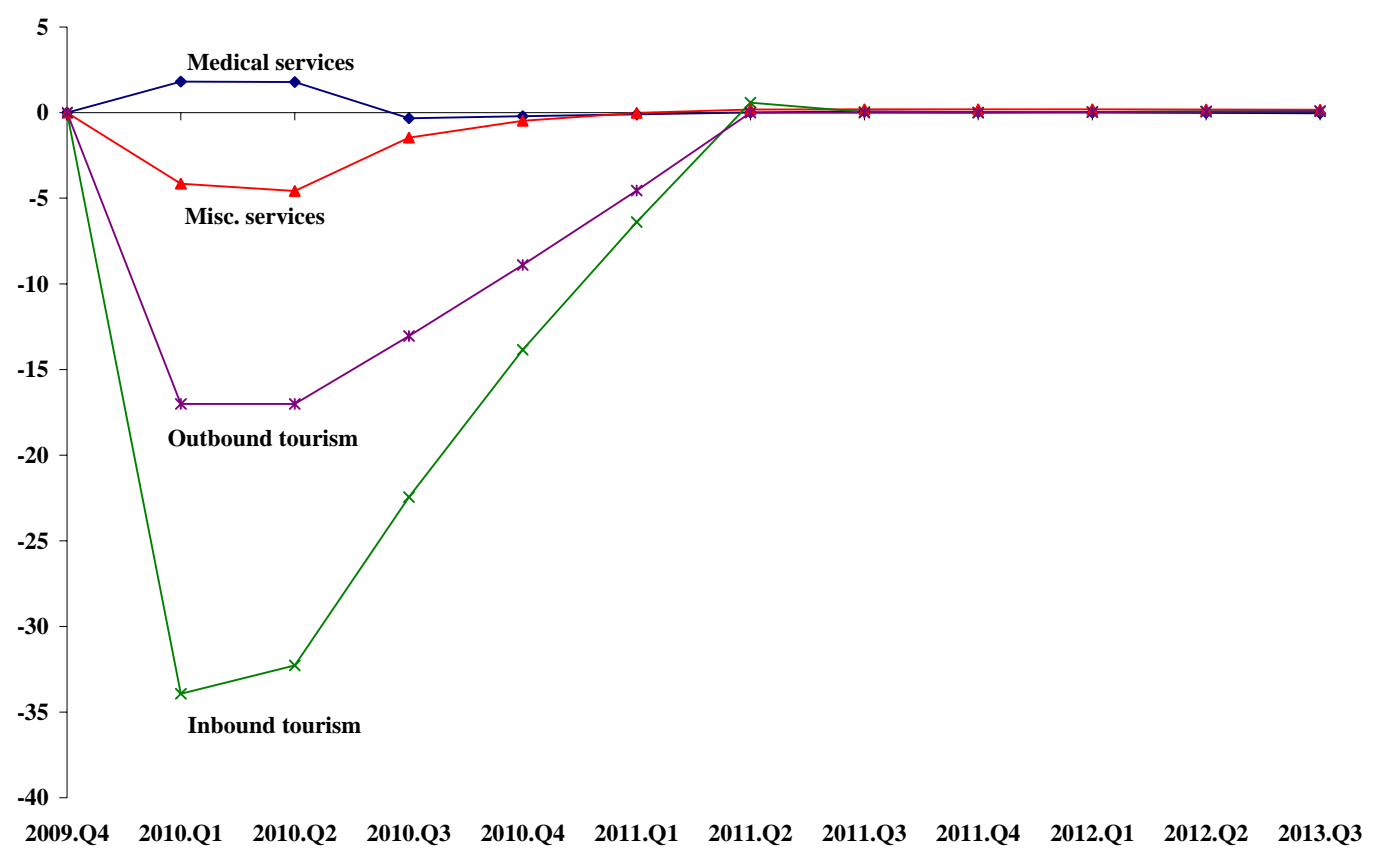

Chart 8. Effects of the hypothetical epidemic on output of investment-related industries (percentage deviations from baseline)

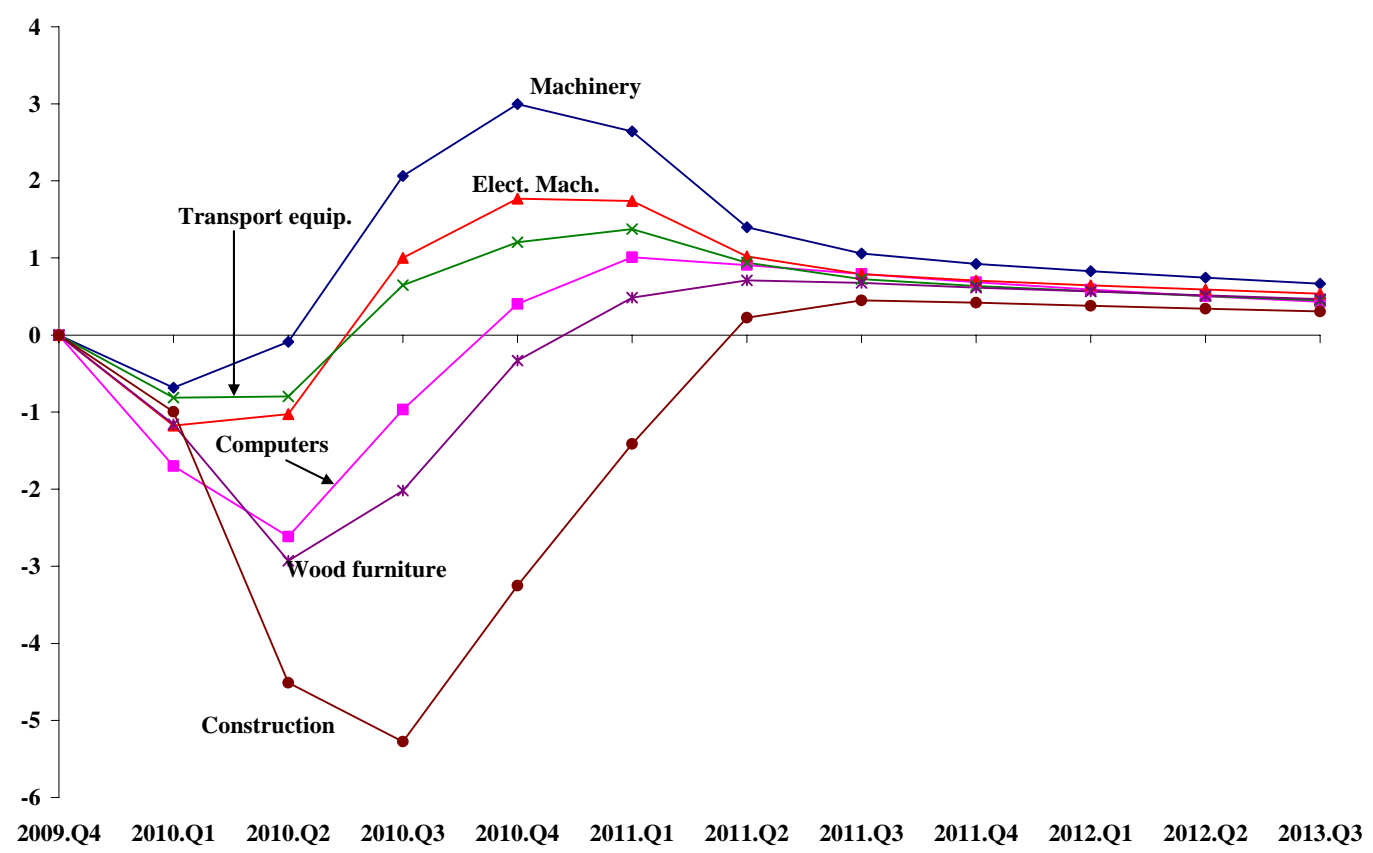


Chart 9. Effects of the hypothetical epidemic on output of highly protected importcompeting industries (percentage deviations from baseline)

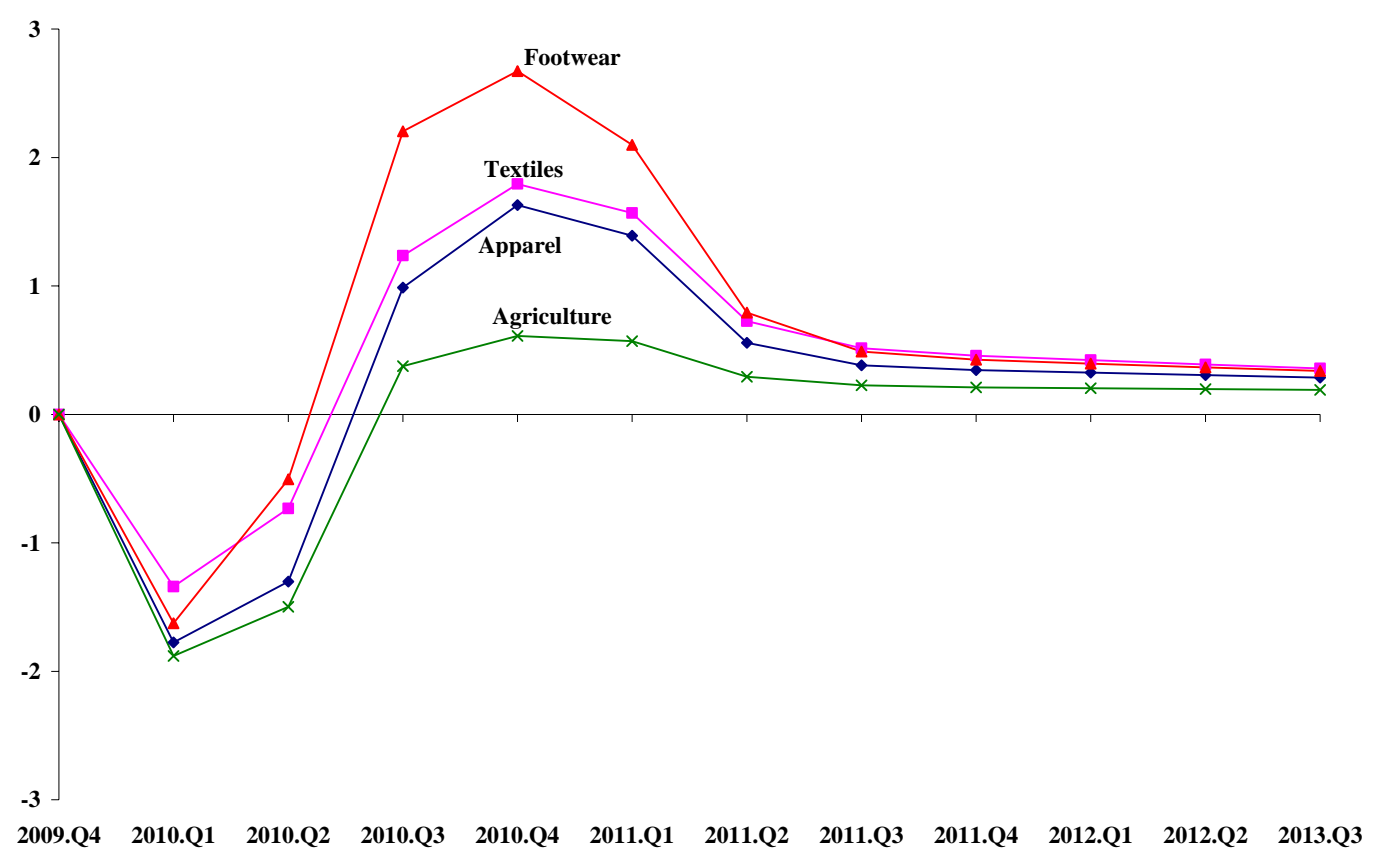

Chart 10. Effects of the hypothetical epidemic on output of other import-competing industries (percentage deviations from baseline)

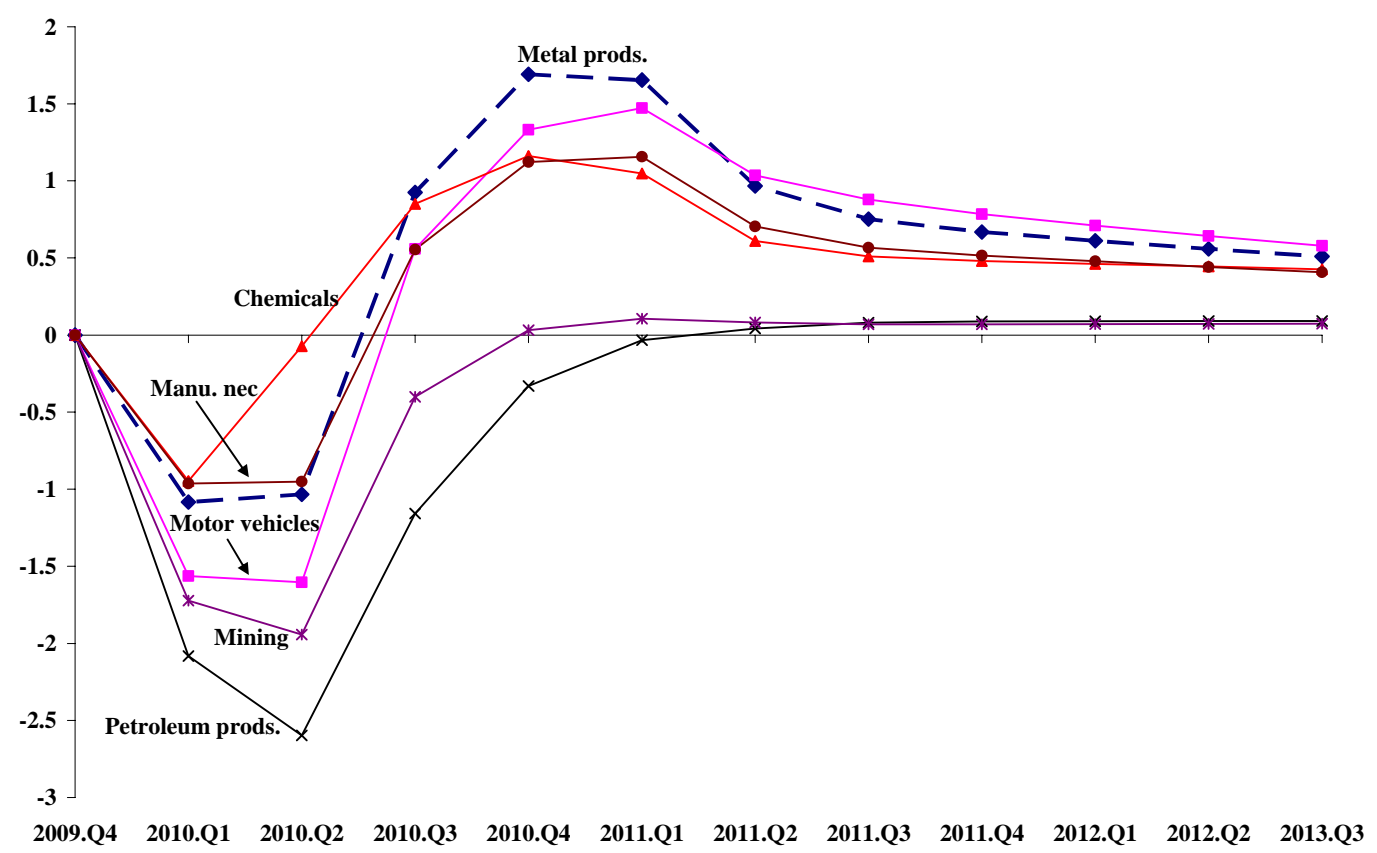


Chart 11. Effects of the hypothetical epidemic on output of government-related service industries (percentage deviations from baseline)

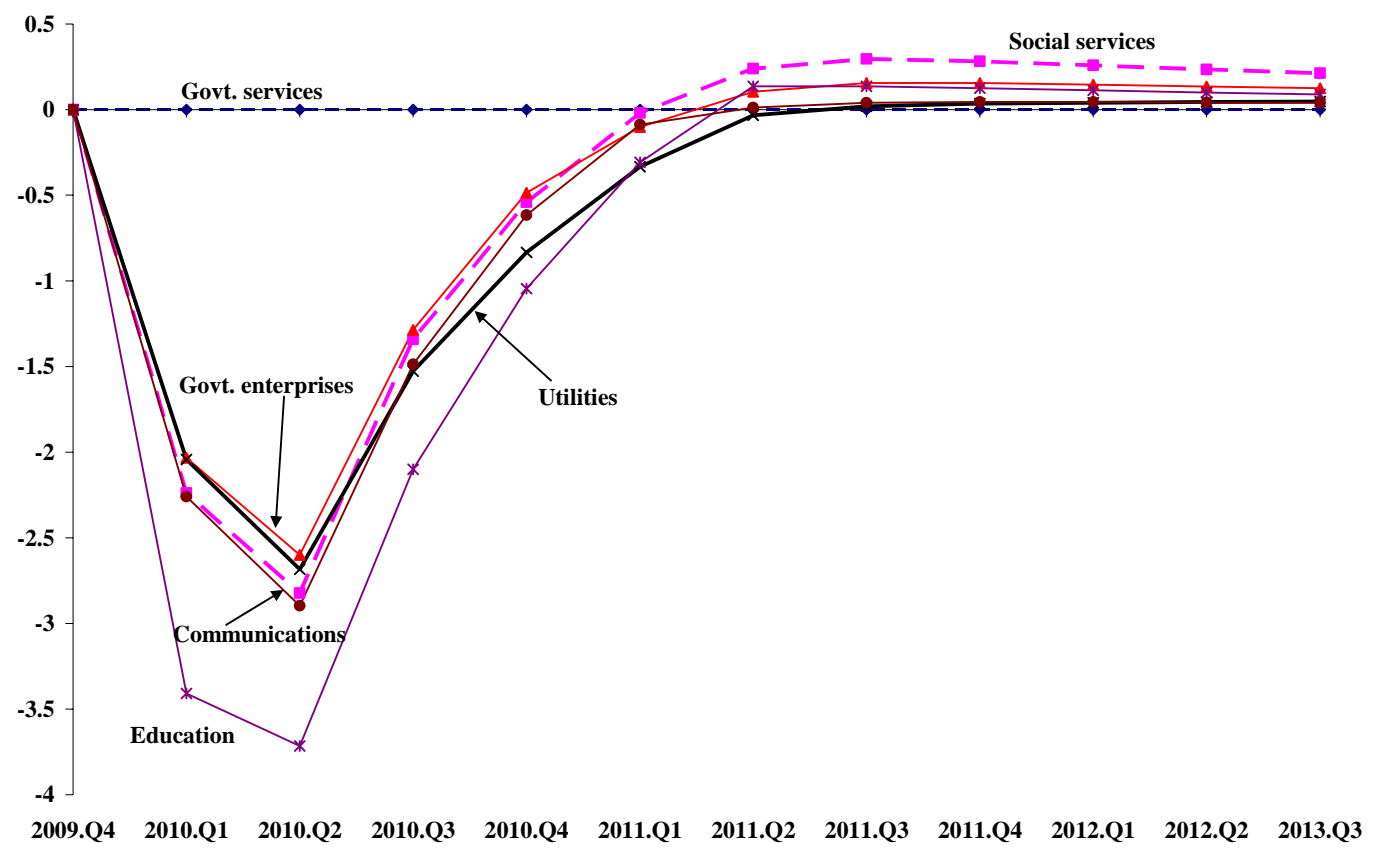

Chart 12. Effects of the hypothetical epidemic on output of private-sector service industries (percentage deviations from baseline)

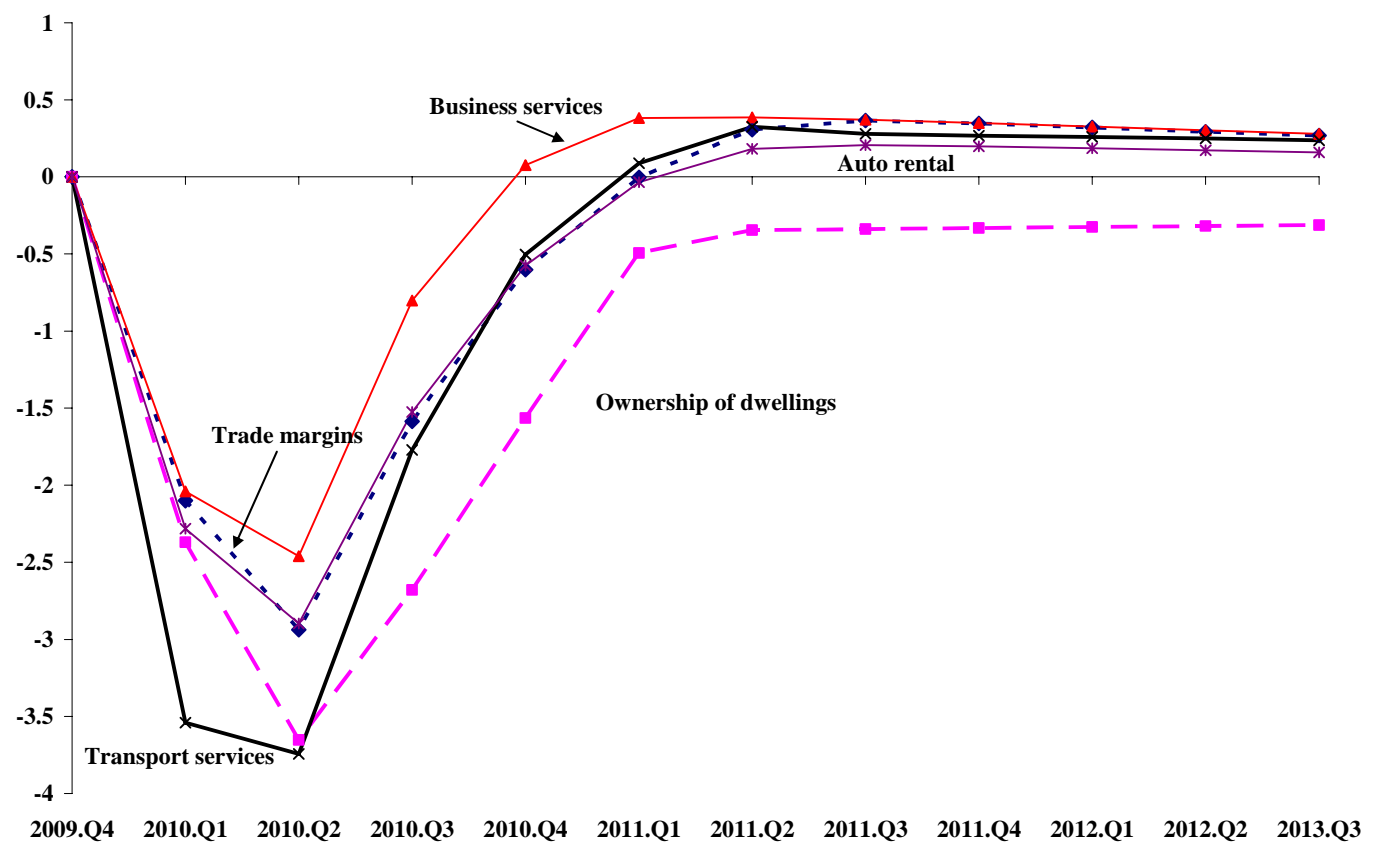


This reflects a low real exchange rate (Chart 6) which facilitates exports of the products of these industries and inhibits imports.

Charts 9 and 10 show that import-competing industries are adversely affected in the short run by the hypothetical epidemic. This is mainly through the contraction of economic activity. By 2010.Q3, output of most of these industries is above baseline: real devaluation improves their competitive position against imports. Exceptions are Mining (mainly crude oil) and Petroleum products which do not return to baseline until 2011.Q1. Output of these products is related mainly to economic activity, with import shares in the domestic market responding only sluggishly to changes in the real exchange rate.

Charts 11 and 12 show results for service industries. With two exceptions, output of these industries dips well below baseline in 2010.Q1 and 2010.Q2, recovers in the second half of 2010 and moves slightly above baseline in 2011. The first exception is Government services (defense, public administration, etc). This industry shows zero output deviations because its entire sales are to government consumption which we assume is unaffected by the epidemic. The second exception is Ownership of dwellings, the output of which is the shelter provide by the housing stock in use. Following the pattern of other service industries, the output of Ownership of dwellings dips below baseline in 2010.Q1 and 2010.Q2. However, unlike other service industries, the recovery in the second half of 2010 and in 2011 in insufficient to move output above baseline. The reason is that the epidemic-related investment slump in 2010 leaves the housing stock, and therefore the output of the Ownership industry, below baseline in 2011.

\section{Relative importance of individual shocks for aggregate employment}

Charts 13 to 15 indicate the relative importance of the different shocks in determining the overall employment effects. We introduce the shocks sequentially with the effect of each set of shocks being revealed by comparison of results in successive simulations. The order in which the shocks are introduced is arbitrary. Fortunately the ordering is not important in the calculation of the effects of each set of shocks.

The solid line in Chart 13 shows the effects of the collapse of international tourism (S1) alone while the dotted line shows the combined effects of the tourism and labor-input shocks, (S1) plus (S2). The chart indicates that the tourism shocks are a major contributor to the short-run employment effects of the hypothetical epidemic. Out of the 2.1 per cent employment reduction in 2010.Q2 (Chart 1), 1.0 percentage points are contributed by these shocks. Comparison of the dotted line in Chart 3 with the solid line shows that the labor-input shocks (S2) are a relatively minor contributor to the aggregate employment result. In 2010.Q2 the labor-input shocks move employment down by an extra 0.2 percentage points, from -1.0 per cent to -1.2 per cent.

Comparison of the dotted and solid lines in Chart 14 shows that increased medical expenditures initially (that is, in 2010.Q1) have almost no effect on aggregate employment, but then in 2010.Q2 to 2011.Q1 they have a small negative effect, and finally in 2011.Q2 to 2012.Q2 they have a small positive effect.

The fact that increased medical expenditures have only a negligible effect on aggregate employment in 2010.Q1 is not surprising. In our modeling we assume that 
Chart 13. Effects of tourism (S1) and productivity (S2) shocks on aggregate employment (percentage deviations from baseline)

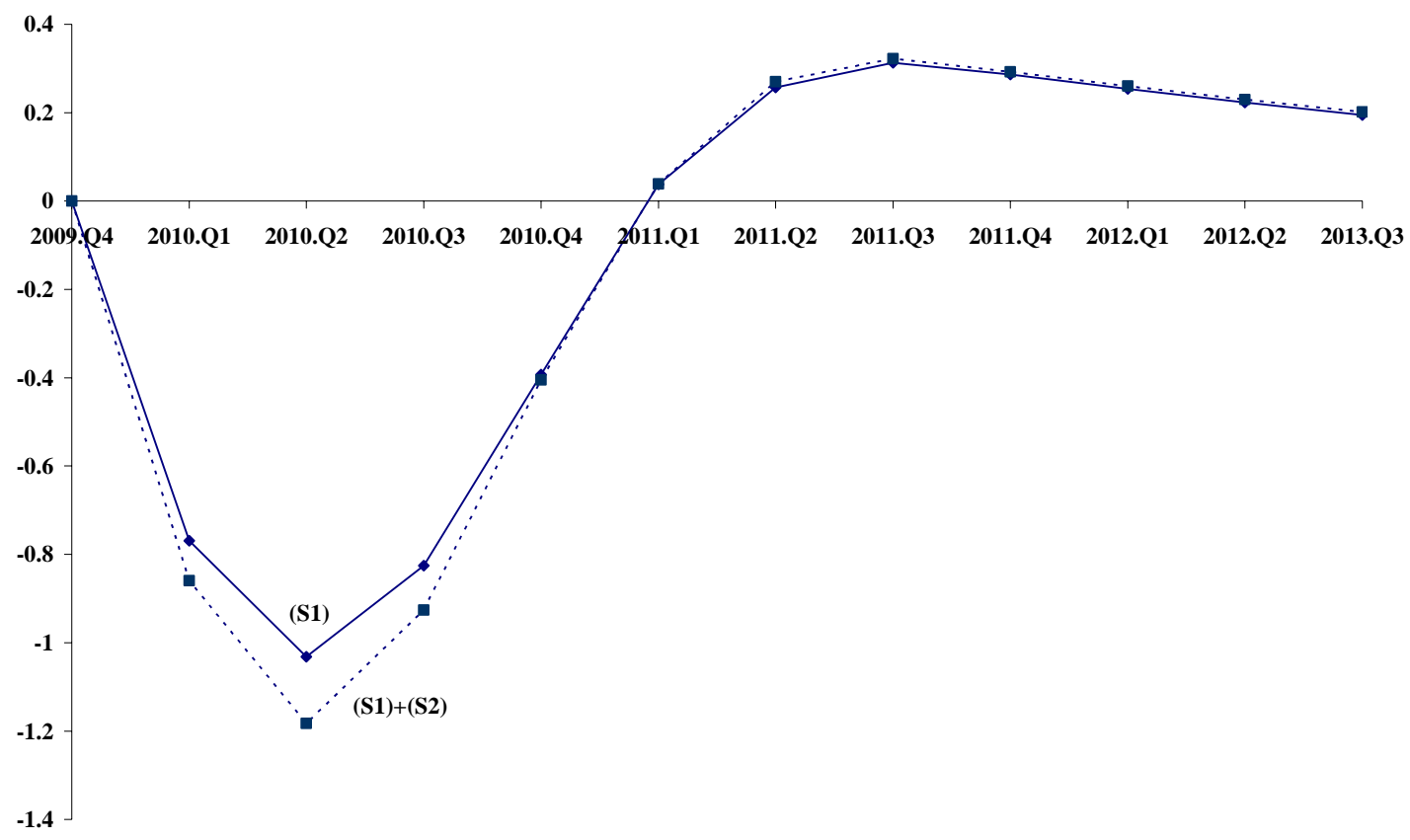

Chart 14. Revealing the effects of medical expenses (S3) on aggregate employment (percentage deviations from baseline)

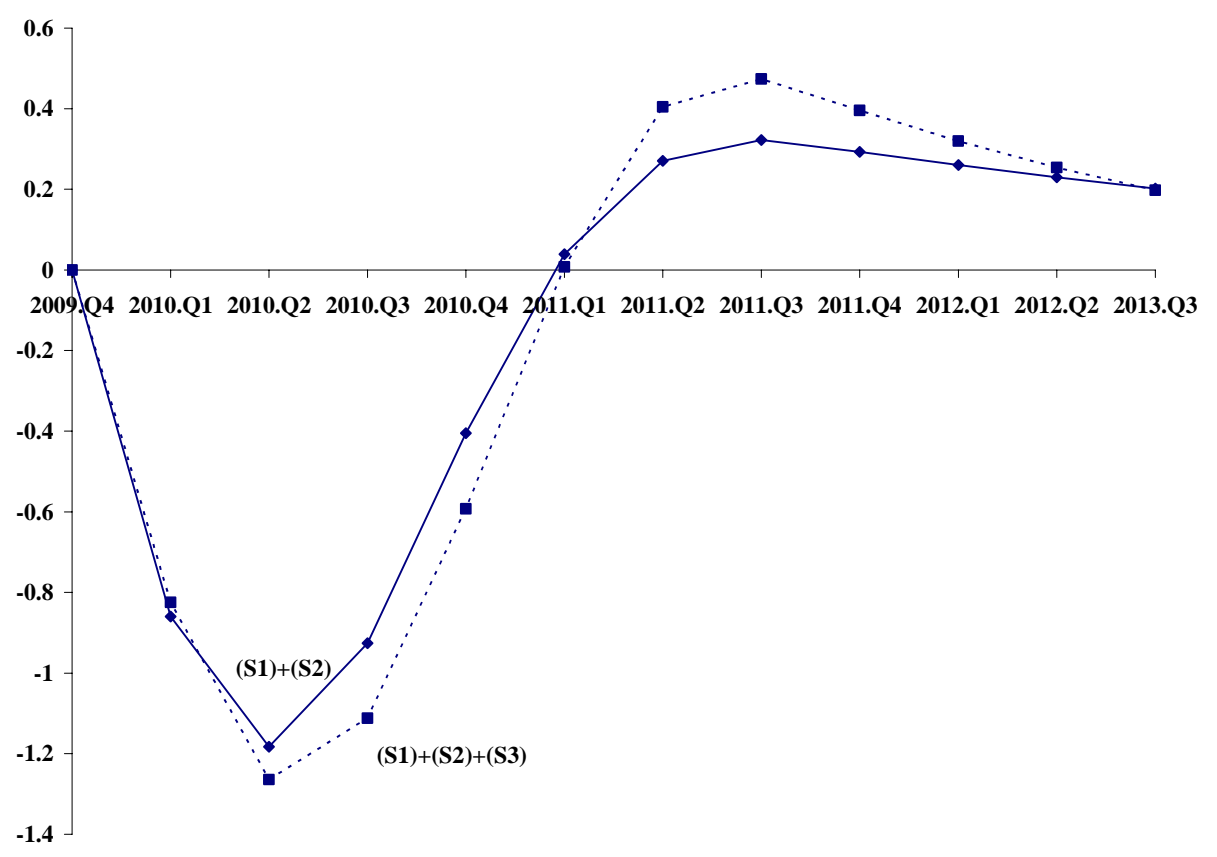




\section{Chart 15. Revealing the effects of cuts in leisure-related expenditures (S4) on aggregate employment (percentage deviations from baseline)}

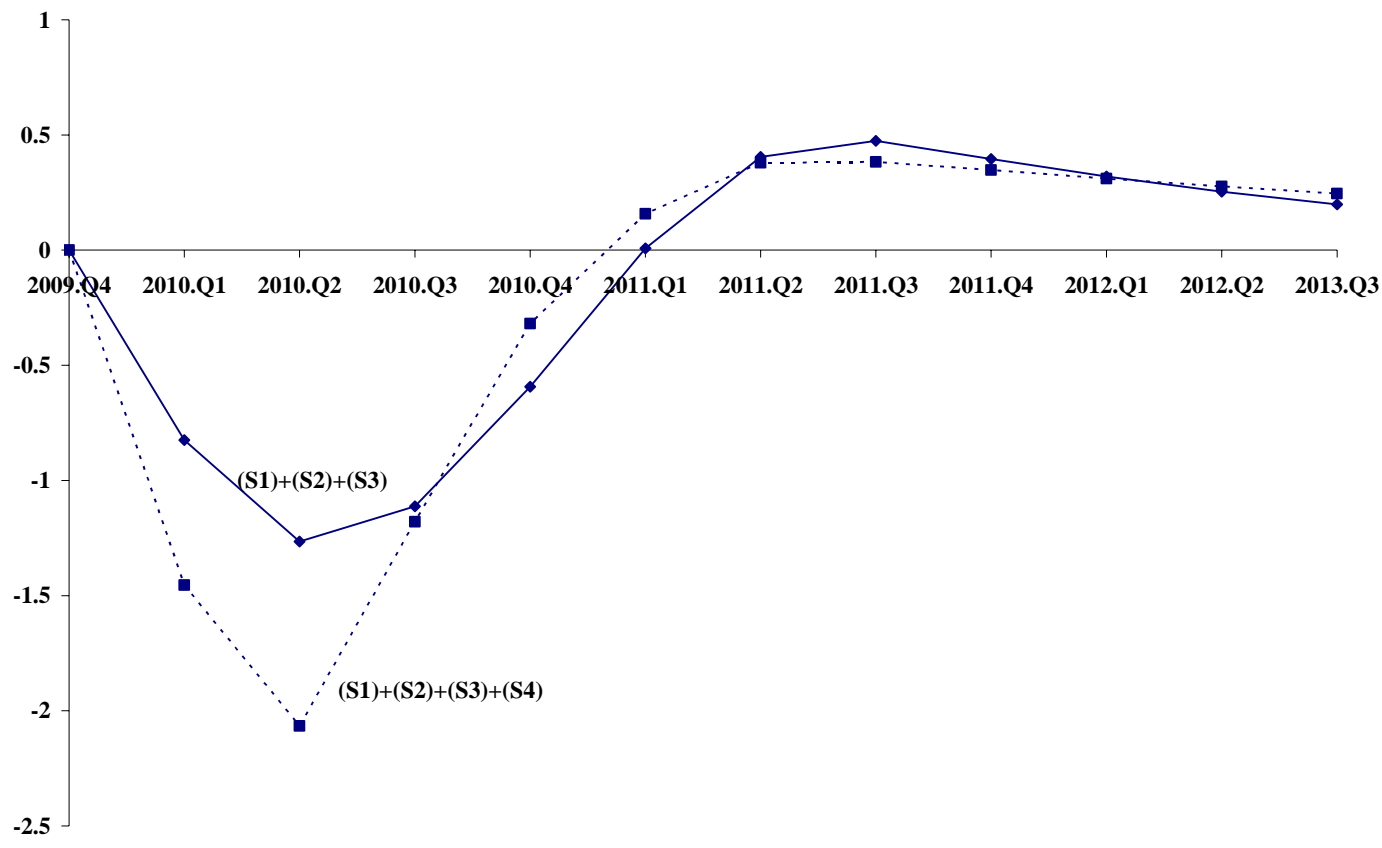

households finance extra medical expenditures by diverting expenditures away from other goods and services, with no direct change in aggregate household demand. This switch in expenditures has a minor positive effect on employment because medical services are labor-intensive relative to other consumer goods and services. However, in our simulation this minor positive effect is offset by a minor negative effect: we assume that with an upsurge in the demand for medical services there is an increase in hours of work per medical employee which damps job creation in the medical sector.

The diversion of household expenditures towards medical services causes additional excess capacity to appear in other consumer sectors in 2010.Q1. This reduces investment in these sectors in subsequent quarters. We assume that there is no offsetting effect from the medical sector where it is recognised that the upsurge in demand for medical services is temporary. Thus there is a net reduction in aggregate investment. In the quarterly version of USAGE, aggregate employment in the short run is determined mainly by movements in aggregate demand. The net reduction in aggregate investment then explains why the dotted line in Chart 14 lies below the solid line for the period 2010.Q2 to 2011.Q1.

Reduced investment in 2010 leaves the economy short of capital in 2011. Thus, the diversion in 2010 of expenditures towards medical services causes aggregate investment to be stronger in 2011.Q2 to 2012.Q2 than it otherwise would have been. This takes the dotted line in Chart 4 for this period above the solid line.

Consistent with the short-run results being demand driven, Chart 15 indicates that diversion of household expenditures on leisure activities into savings (S4) has a significant negative effect on employment in the first half of 2010: for 2010.Q2 the 
dotted line in Chart 15 lies 0.8 percentage points below the solid line. The wage mechanism, explained earlier, means that when demand for leisure activities recovers in the second half of 2010, employment temporarily moves above where it would have been without the contraction in demand for these activities, that is, the dotted line in Chart 15 moves above the solid line.

\section{Summary and concluding remarks}

In this paper we used a quarterly CGE model to simulate the effects of a hypothetical H1N1 epidemic infecting about 90 million Americans and causing symptoms of various levels of severity in about 60 million. The use of a model with quarterly periodicity rather than the usual annual periodicity allowed us to capture the short-run nature of an epidemic. Such an event would have its economic effects concentrated over no more than one or two quarters.

Specifically, we assumed that the epidemic lasts for two quarters and causes: reductions of 34 and 17 per cent in inbound and outbound international tourism; a loss of 0.4 per cent in labor productivity; a 2.4 per cent surge in demand for hospital and other medical services; and a 10 per cent cut in expenditures by households on leisure activities involving public gatherings. Table 3 is a summary of our macroeconomic results. It shows quite severe effects at the height of the epidemic (peak quarter) including a 2.1 per cent reduction in employment. Averaged over the epidemic year the effects are considerably damped. In the year following the epidemic, the macroeconomic effects are mostly positive. By reducing wage rates, the epidemic improves the competitive position of the U.S. economy in the post-epidemic year. It also boosts investment in the postepidemic year. This is explained by a capital shortage reflecting reduced investment in the epidemic year.

Our modeling showed substantial direct epidemic-related effects on several industries: positive for medical services; negative for inbound and outbound tourism; and negative for miscellaneous services which includes leisure activities involving public gatherings. For other industries, the results were fairly uniform with variations reflecting macroeconomic effects. Construction was particularly adversely affected in the short run by weakness in investment. Trade-exposed industries showed rapid recovery facilitated by real devaluation. For nearly all industries, the epidemic produced a sharp but shortlived downturn.

Although we looked at only one epidemic scenario, our analysis can be extended to cover other scenarios. This can be done by using the results for individual shocks presented in the last part of section 4. For example, Chart 13 implies that cuts of 34 and 17 per cent in inbound and outbound tourism (S1) sustained over two quarters would cause reductions in aggregate employment in the two quarters of 0.8 and 1.0 per cent. While responses from models such as USAGE are not completely linear, we can be confident that if the tourism cuts were 50 per cent greater (51 and 25.5 per cent rather than 34 and 17 per cent) then our model would imply additional reductions in aggregate employment of approximately 0.4 and 0.5 per cent. Similarly, Chart 13 implies that a productivity reduction of 0.41 per cent sustained over two quarters (S2) would cause reductions in aggregate employment in the two quarters of 0.1 and 0.2 per cent (the gaps 
Table 3. USAGE results for the effects of an H1N1 epidemic (Percentage deviations from baseline)

\begin{tabular}{lccc}
\hline Variable & Peak quarter & Epidemic year & Next year \\
\hline Employment & -2.1 & -1.3 & 0.3 \\
GDP & -2.6 & -1.6 & 0.2 \\
Private consumption & -3.2 & -2.1 & -0.1 \\
Investment & -4.3 & -3.1 & 0.5 \\
Exports & -4.7 & -2.7 & 1.0 \\
Imports & -5.7 & -4.5 & -0.3 \\
\hline
\end{tabular}

between the dotted and solid lines). If the productivity cut were 50 per cent greater ( 0.615 per cent rather than 0.41 per cent) then there would be additional reductions in aggregate employment of approximately 0.05 and 0.10 per cent. Overall, our results for individual shocks indicate that the macroeconomic consequences of an epidemic are much more sensitive to demand-side effects such as reductions in international tourism and leisure activities than to supply-side effects such as reductions in productivity. This suggests that demand stimulus policies might be an appropriate economic response to a serious epidemic.

\section{References}

Bloom, E., V. d. Wit and M. J. C-S. Jose (2005), "Potential economic impact of an Avian Flu pandemic on Asia”, ERD Policy Brief Series No. 42, Asian Development Bank, Manila, available at http://www.adb.org/documents/EDRC/Policy_briefs/PB042.pdf .

Congressional Budget Office (2006), A Potential Influenza Pandemic: Possible Macroeconomic Effects and Policy Issues, The Congress of the United States, Washington, D.C.

Dixon, P.B. and M.T. Rimmer (2002), Dynamic General Equilibrium Modelling for Forecasting and Policy: a Practical Guide and Documentation of MONASH, Contributions to Economic Analysis 256, North-Holland Publishing Company, pp.xiv+338.

Dixon, P.B., K.R. Pearson, M.R. Picton and M.T. Rimmer (2005), "Rational expectations for large CGE models: a practical algorithm and a policy application”, Economic Modelling, Vol. 22(6), December, pp.1001-1019.

McKibbin, Warwick J., and Alexandra A. Sidorenko (2006). “Global Macroeconomic Consequences of Pandemic Influenza.” Lowry Institute Analysis, February, pp. 79, available at http://www.brookings.edu/views/papers/mckibbin/200602.pdf .

Molinari, N. A. M., I. R. Ortega-Sanchez, M. L. Messonnier, W. W. Thompson, P. M. Wortley, E. Weintraub, and C. B. Bridges (2007), "The annual impact of seasonal influenza in the US: Measuring disease burden and costs”. Vaccine 25 (27):508696. 
Reed C, F.J. Angulo, D.L. Swerdlow, M. Lipsitch, M.I. Meltzer, D. Jernigan and L. Finelli (2009), "Estimates of the prevalence of pandemic (H1N1) 2009, United States, AprilJuly 2009”, Emerging Infectious Diseases, Vol. 15(12), pp.2004-7.

United States International Trade Commission (2004, 2007, 2009), The Economic Effects of Significant U.S. Import Restraints: Fourth, Fifth and Sixth Updates, Investigation No. 332-325, Publication 3701, 3906 \& 4094.

\title{
Appendix
}

\section{H1N1 epidemic: Setting the shocks for economic modeling}

\author{
Bumsoo Lee \\ University of Illinois at Urbana-Champaign \\ and \\ Todd Muehlenbeck \\ CREATE, University of Southern California
}

\section{Data description}

A severe outbreak of H1N1 influenza, declared as the first pandemic in the $21^{\text {st }}$ Century by the World Health Organization (WHO), can have substantial economic consequences. We model economic shocks in two aspects, supply- and demand-side impacts. Supply-side economic shocks come from the temporary or permanent loss of labor, caused by deaths and missed workdays. Demand-side impacts include reduced tourism and the demand for other activities involving public gatherings. The estimation of the economic impacts requires not only a sophisticated economic model but also reasonable disease outbreak scenarios and behavioral parameters that can be used to build the most likely exogenous shocks to the economic system. The disease outbreak scenarios for this study came from an agent-based disease outbreak simulation developed at PACER by Josh Epstein and Jon Parker. We also collected supplementary disease and behavioral parameters from existing data of the current H1N1 influenza and other historical epidemics.

Agent-based epidemic modeling of H1N1 influenza involved ten simulation runs. In all simulation results, the epidemic reached the peak during the third and fourth quarters and died out in the sixth or seventh quarter. As there was little variation in the simulation results, we used mean values of the ten simulations in making the disease outbreak scenario for this study. It was estimated that about 92 million Americans would be infected and about 62 millions among them would be symptomatic over a period of seven quarters. Nearly all of the infections (89 million infected and 60 million symptomatic persons) are in the third and fourth quarters. Thus, all of our analysis hereafter will focus on these two quarters.

We then need to determine what proportion of symptomatic persons seek medical attention, are hospitalized, or die to estimate the loss of labor force and medical costs. To compute symptomatic case-hospitalization ratio (sCHR) and symptomatic case-fatality ratio (sCFR), we used estimates of $\mathrm{H} 1 \mathrm{~N} 1$ patients, hospitalizations and deaths during 
April-July 2009 by the scientists in the Centers for Disease Control and Prevention (CDC) (Reed et al. 2009). We used these estimates instead of the CDC's Surveillance data because the surveillance data are likely to underestimate true numbers for many reasons. For instance, not all symptomatic patients seek medical care and specimen collection and testing may have been done only for a small proportion of patients who sought medical care. Table 1 presents the CDC estimates and computed sCHR and sCFR by age group.

These parameters further transformed into three relevant age categories for economic analysis: the young (0 to 17), working age (18 to 64), and elderly (65 and more). In doing so, we assumed that persons in the 5 - 24 age group are uniformly distributed across years, meaning that $35 \%$ are counted as working age. Table 2 shows estimated number of symptomatic patients, hospitalizations, and deaths by three age groups during the third and fourth quarters. If hospitalization and death rates remain the same as in the early period, we expect there to be 269,706 hospitalized persons and 15,655 mortalities in a scenario of about 60 million symptomatic cases for the two peak quarters.

While the number of working age deaths directly translates into the permanent loss of labor, temporary labor productivity loss includes both missed workdays of patients and parental leaves for sick children. Average missed workdays per case vary depending on the severity of cases. We applied Molinari et al. (2007)'s estimate of missed work days per working age person by level of treatment for seasonal flu: a half day for patients with symptoms who do not seek medical attention; 2.4 days for patients who visit a doctor's office but are not hospitalized; and 13.9 days for patients who are hospitalized. The same number of lost work days was applied to hospitalized patients whether they survive or die. We assumed that $50 \%$ of symptomatic persons seek medical care based on Reed et al. (2009)'s finding. They estimated that $42 \%$ to $58 \%$ of persons with flu sought medical attention. Combining all level of patients, the total number of missed work days due to sickness of workers is estimated at 42,234,000.

The calculation of parental leaves for sick children is less straightforward. To estimate what proportion of families with ill children has to involve parental leaves, we used the 2007 American Community Survey data. We considered families with a single employed parent and married-couple families in which both parents work. We assumed that one parent needs to miss work to take care of sick children in these types of families and they comprise $70 \%$ of all families with children under 18 years old. Based on Molinari et al. (2007)'s finding, when a parent takes care of a sick child, he/she is assumed to miss a comparable number of work days except in the case of hospitalization, in which case half as many days are missed. The resulting estimate is 31,802,000 parental leaves for sick children. Combining all missed work days due to sick workers and children, we estimate total missed working days at 74,037,000.

Calculating direct costs for medical treatment is relatively straightforward. We simply multiplied the number of persons by level of treatment by the cost of treatment. We obtained average medical costs per case by treatment level from a CDC study on seasonal influenza (Molinari et al., 2007), which calculated medical costs using the Medstat Marketscan database. Table 3 shows treatment cost per person and estimated total medical costs. 
Table A1. Symptomatic case-hospitalization and -fatality ratios by age group

\begin{tabular}{|c|c|c|c|c|c|c|c|c|}
\hline & \multicolumn{3}{|c|}{ Estimates by $\mathrm{CDC}^{\mathrm{a}}$} & \multicolumn{2}{|l|}{ sCHR and sCFR } & \multicolumn{3}{|c|}{ Share of infections by age group } \\
\hline & No. case & No. & Deaths & $\mathrm{sCHR}^{\mathrm{b}}$ & $\mathrm{sCFR}^{\mathrm{b}}$ & Symptomatic & Hospitalization & Deaths \\
\hline & Patients & Hospitalization & & Hospitalization & Deaths & Patients & & \\
\hline Total & $3,052,768$ & 13,764 & 800 & $0.451 \%$ & $0.026 \%$ & $100.0 \%$ & $100.0 \%$ & $100.0 \%$ \\
\hline $0-4$ & 397,033 & 2,768 & 20 & $0.697 \%$ & $0.005 \%$ & $13.0 \%$ & $20.1 \%$ & $2.5 \%$ \\
\hline $5-24$ & $1,820,284$ & 4,991 & 139 & $0.274 \%$ & $0.008 \%$ & $59.6 \%$ & $36.3 \%$ & $17.4 \%$ \\
\hline $25-49$ & 612,862 & 3,440 & 359 & $0.561 \%$ & $0.059 \%$ & $20.1 \%$ & $25.0 \%$ & $44.9 \%$ \\
\hline $50-64$ & 180,297 & 1,912 & 206 & $1.060 \%$ & $0.114 \%$ & $5.9 \%$ & $13.9 \%$ & $25.8 \%$ \\
\hline $65+$ & 42,292 & 654 & 75 & $1.546 \%$ & $0.177 \%$ & $1.4 \%$ & $4.8 \%$ & $9.4 \%$ \\
\hline
\end{tabular}

Table A2. sCHR, sCFR, and estimates by functional age group

\begin{tabular}{|c|c|c|c|c|c|}
\hline & \multicolumn{2}{|l|}{ sCHR and sCFR } & \multicolumn{3}{|c|}{ Cases by functional age group } \\
\hline & sCHR & sCFR & Symptomatic & Hospitalization & Deaths \\
\hline & Hospitalization & Deaths & Patients & & \\
\hline Total & $0.451 \%$ & $0.026 \%$ & $59,814,844$ & 269,706 & 15,655 \\
\hline Young $(0-17)$ & $0.38 \%$ & $0.01 \%$ & $30,962,218$ & 117,800 & 2,162 \\
\hline Working age $(18-64)$ & $0.50 \%$ & $0.04 \%$ & $28,023,971$ & 139,092 & 12,024 \\
\hline Elderly $(65+)$ & $1.55 \%$ & $0.18 \%$ & 828,654 & 12,814 & 1,470 \\
\hline
\end{tabular}


Table A3. Medical costs by treatment level

\begin{tabular}{llll}
\hline Type of Treatment & No. cases (thousands) & Cost per person & Total cost (\$ millions) \\
\hline Not treated & 29,907 & 3 & 89.7 \\
Outpatient & 29,622 & 293 & $8,679.3$ \\
Hospitalized and Survived & 254 & 18,298 & $4,648.6$ \\
Death & 16 & 46,120 & 722.0 \\
\hline Total & 59,799 & & $14,139.6$ \\
\hline
\end{tabular}

a. In 2003 dollars.

\section{Appendix references}

Molinari, N. A. M., I. R. Ortega-Sanchez, M. L. Messonnier, W. W. Thompson, P. M. Wortley, E. Weintraub, and C. B. Bridges. 2007. The annual impact of seasonal influenza in the US: Measuring disease burden and costs. Vaccine 25 (27):50865096.

Reed, C, FJ Angulo, DL Swerdlow, M Lipsitch, MI Meltzer, D Jernigan, and L Finelli. 2009. Estimates of the Prevalence of Pandemic (H1N1) 2009, United States, April-July 2009. Emergent Infectious Diseases (forthcoming). 